\section{Autoantibodies binding to citrullinated telopeptide of type II collagen and to cyclic citrullinated peptides predict synergistically the development of seropositive rheumatoid arthritis}

\author{
Marja-Kaisa Koivula, Markku Heliövaara, Jarmo Ramberg, \\ Paul Knekt, Harri Rissanen, Timo Palosuo, Juha Risteli
}

This paper is freely available online under the BMJ Journals unlocked scheme, see $\mathrm{http}$ ://ard.bmj.com/info/unlocked.dt|
See end of article for authors' affiliations

Correspondence to:

Juha Risteli, MD, PhD,

Professor of Clinical

Chemistry, University of

Oulu, PO Box 5000, FI-

90014 University of Oulu,

Finland; juha.risteli@oulu.fi

Accepted 15 April 2007

Published Online First

27 April 2007

.......................

\begin{abstract}
Objectives: To find out whether autoantibodies to citrullinated telopeptides of type I and II collagens and to cyclic citrullinated peptides (CCPs) predict the development of rheumatoid arthritis (RA).

Methods: A case-control study (matched for sex, age and municipality) was nested within a Finnish cohort of 19072 adults who had neither arthritis nor a history of it at the baseline examination during 1973-7. 124 subjects developed RA by late 1989, and of these, 89 were positive for rheumatoid factor (RF). Preillness serum specimens were analysed for autoantibodies against arginine (A)- or citrulline (C)-containing synthetic telopeptides using a chemiluminescence method and for anti-CCPs Mark2 with an enzyme-linked immunosorbent assay method.

Results: The mean levels of autoantibodies to citrulline-containing telopeptides and the C/A ratios of type I and II collagens and to CCP were higher in subjects who later developed RF-positive RA. In the highest tertiles of C/A (I), C/A (II) ratios and anti-CCPs levels, the relative risk of RF-positive RA was significantly increased. In the multifactorial model, only anti-CCPs retained its statistical significance. However, the interaction term of C/A (II) ratio and anti-CCPs proved to be statistically significant $(p=0.02)$. The subjects ranked into the highest tertiles of both C/A (II) ratio and anti-CCPs had an odds ratio of $20.06(95 \%$ confidence interval, 4.37 to 92.06) of developing RF-positive RA compared with those in the lowest tertiles of these antibodies. None of the autoantibodies predicted RF-negative RA.

Conclusion: Autoantibodies to citrullinated telopeptides of type I and II collagen and to CCPs exert a synergistic effect on the risk of seropositive RA.
\end{abstract}

$\mathrm{R}$ heumatoid arthritis (RA) is a systemic autoimmune disease of unknown aetiology, characterised by chronic joint inflammation that often leads to joint destruction. Both environmental and genetic factors play a role in the aetiopathogenesis of the disease. ${ }^{1}$ It was recently reported that one environmental factor, smoking, can trigger immune reactions characteristic of $\mathrm{RA}^{2}$ and the appearance of antibodies to citrullinated proteins. ${ }^{3}$ Citrullination of proteins is a normal post-translational process occurring late during the protein lifespan-for example in filaggrin and vimentin during their apoptotic degradation. Several autoantibodies found in RA are directed to epitopes in citrullinated proteins. ${ }^{4}$ Citrulline is formed from arginine residues in peptides or proteins by the enzyme peptidylarginine deiminases (PADs). There are at least 5 genetically different forms of PADs, of which two isotypes, PAD2 and PAD4, have been found in monocytes and macrophages of inflamed synovium. There is also polymorphism related to rheumatoid arthritis. ${ }^{6-8}$ It has been hypothesised that during rheumatic synovitis, PAD is released into the extracellular space inducing locally citrullination of arginine residues in several proteins-for example in vimentin, fibrin and fibrinogen, fibronectin, $\alpha$-enolase, keratin, initial factor $4 \mathrm{Gl}$ and finally type I and II collagens. ${ }^{4}{ }^{5}$ 9-15

Several autoantibodies, such as RF and filaggrin-related antibodies (antikeratin antibodies, antiperinulear factor and antibodies to human filaggrin) as well as anti-CCPs have been shown to precede the onset of clinical RA, often by many years. ${ }^{16-21}$ The frequency of positive reactions is dependent on

the time elapsed from taking the serum specimen to the onset of clinical disease..$^{17}$

Anti-CCPs antibodies are currently the most specific markers of RA and have been widely used for diagnostic purposes. ${ }^{20} 22$ According to the recent review of Avouac et $a l^{23}$ the mean $( \pm \mathrm{SD})$ sensitivity value for the second-generation anti-CCP assays was $68( \pm 15) \%$ in 58 articles published in 1999-2006. The sensitivity of anti-CCP2 is close to that of RF, whereas the specificity in differentiating RA from other rheumatic diseases is strikingly high, $96( \pm 3) \%$.

The inciting stimuli for the production of antibodies to citrullinated peptide and protein epitopes are not known; nor is it known whether these antibodies participate in the rheumatic inflammation. On the other hand, it has long been supposed that autoimmunity against collagens might be involved in the pathogenesis of RA. In our laboratory, the enzyme-linked immunosorbent assays (ELISAs) were first used to demonstrate the existence of autoantibodies reacting against citrullinated peptides derived from type I and type II collagens in patients with RA. ${ }^{15}$ Second, we developed more sensitive methods for these autoantibodies which were used in this study. In these automatic CLIA methods, $38 \%$ of early RA patients showed increased binding of synthetic citrullinated carboxytelopeptide derived from the $\alpha$ l chain of type I collagen. For corresponding

Abbreviations: CCP, cyclic citrullinated peptide; ELISA, enzyme-linked immunosorbent assay; PAD, peptidylarginine deiminase; RA, rheumatoid arthritis; RF, rheumatoid factor 
carboxytelopeptide from the $\alpha$ l chain of type II collagen, 35 patients' sera out of 120 early RA patients bound the citrullinated peptide more strongly than the arginine peptide. ${ }^{24}$

Many antigens will be citrullinated, and many antibodies are formed against these antigens. The anti-CCP2 is an artificial antigen of unknown origin that is kept secret for commercial reasons. Now, we want to test whether citrullinated collagen peptides are also predictive for development of RA and add to the predictive power of anti-CCP2.

\section{SUBJECTS AND METHODS Patients and controls}

During 1973-7, the Social Insurance Institution's Mobile Clinic Unit carried out multiphasic health examinations in 12 municipalities in four regions of Finland. ${ }^{25-27}$ In each of the four regions, all inhabitants or a random sample of inhabitants of one rural municipality and one urban or semi-urban municipality as well as the employees of one factory were invited to attend the examination. ${ }^{25}$ A total of 19518 subjects who were 20 years of age or older (83\% of those invited) participated in the examinations. Of these, 446 had a previous history of inflammatory arthritis and were excluded from the current study. The mean age of the subjects was 45 years (range 20 to 98$)$.

The population at risk ( 19072 subjects) consisted of participants who had no previous history of arthritis or other rheumatic disease, according to the Social Insurance Institution's population register or to a questionnaire administrated at the baseline examination. Morbidity and mortality of all examinees were followed up continuously. Participants in the survey who later developed chronic arthritis were identified by linking the survey data with the Social Insurance Institution's population register up to the end of 1989, using the unique identification code assigned to each Finnish citizen. In Finland, reimbursed drugs are provided for certain rheumatic diseases, including chronic inflammatory rheumatic diseases. Eligibility requires a comprehensive medical certificate written by the attending physician and approved by an expert adviser (specially trained physician) on behalf of the sickness insurance system. Nearly all certificates are based on examinations and follow-up experience at special rheumatology clinics. These written documents were carefully reviewed to identify incident cases of RA on the basis of the following criteria: (a) the patient had been granted the right to specially reimbursed medication because of a physician's diagnosis of clinical RA; (b) there was no history of rheumatoid disease at the health examination; and (c) according to the doctor's certificate, the onset of the disease occurred after the health examination. Information on the RF status was obtained from the certificates. Testing had been performed in several different laboratories. Sufficient information concerning diagnosis and onset of disease was obtained in 124 cases, of which 89 were RF-positive by the time of the diagnosis. ${ }^{16}$

The certificates are written to provide evidence that a patient has the disease and needs treatment, but they are not keyed to any set of criteria. Most patients with RA entitled to reimbursement for drug treatment meet, however, the revised criteria of the American Rheumatism Association, and the sensitivity of the sickness insurance data exceeds $90 \%$ for seropositive RA. ${ }^{28}{ }^{29}$ Half of the RF-negative cases have been reported as having radiographic changes typical for RA. ${ }^{30}$

A nested case-control design was applied to study anti-CCPs for its prediction of clinical RA. Three controls per case were selected by individual matching, using sex, age and municipality as matching factors. Exact matching was performed for sex and municipality, whereas the nearest available matching was used for age within the sex-municipality strata. Matching for municipality also controlled for both the time of the baseline examination and the duration of storage of serum samples. ${ }^{16}$

\section{Assays for detecting autoantibodies against collagen telopeptides}

Blood samples were drawn at the mobile clinic and sera stored frozen at $-20^{\circ} \mathrm{C}$ until used for testing. The principle of assays for detecting autoantibodies against collagen telopeptides has been described previously. ${ }^{24}$ In brief, measurements were carried out with two-site chemiluminescence immunoassays, which detect IgG antibodies against the synthetic C-telopeptides of the $\alpha$ l chain of human type I and II collagens (EKAHDGGRYYXA and EKGPDPLQYMXA, where $X$ denotes arginine or citrulline. Peptides are from NeoMPS, Strasbourg, France). The serum samples were diluted 1:10 and incubated with the above biotinylated peptide and magnetic particles. After subsequent washing, acridinium-labelled anti-human IgG antibodies were added to the reaction mixture. The wells containing the washed magnetic particles with antigen/antibody/complex were transferred to the system luminometer, which automatically injected triggers, initiating the chemiluminescence reaction. Light was quantified by a luminometer and expressed as relative luminescence units (RLU). The system background was measured daily by running the System Performance Controls provided by Nichols Institute Diagnostics (San Clemente, CA). To assure the validity of the results, controls with three different concentrations were measured. These controls included negative, low, and high titres, and their coefficients of variance were between 2 and 15 $\%$ (see table 2 in reference 24 ). We could not analyse A (II) from five sera, A (I) and C (I) from 44 sera due to problems with the instrument. This means that results regarding A/C (I) have become more conservative, and the statistical power is less than for $\mathrm{A} / \mathrm{C}$ (II).

\section{Enzyme immunoassays for anti-CCP2 antibodies}

Anti-CCPs antibodies were measured in duplicates in the sera using the Immunoscan RA (Mark 2) kits from Euro Diagnostica (Malmö, Sweden) according to the manufacturer's instructions. The cutoff limit for the positive result in the assay was $25 \mathrm{U} / \mathrm{ml}$. The standard curve was linear to the level of the provided negative serum, which yielded in 12 successive assays an average $( \pm S D)$ of $12.8( \pm 0.84) \mathrm{U} / \mathrm{ml}$. The interassay variation (reproducibility) for the negative serum was $6.6 \%$, and that for the lowest standard $(25 \mathrm{U} / \mathrm{ml}) 3.2 \%$. Thus, although the absolute levels below the lowest standard may be inaccurate, the ranking is correct for fractile divisions.

\section{Statistical analysis}

Associations between different autoantibodies, antibody ratios, sex and age were assessed with the general linear model. The significance of the differences in mean levels of serum antibodies between RA cases and their individually matched controls was tested by the paired t test. The conditional logistic model $^{31}$ was used to estimate the associations between serum antibody levels and the risk of RA. Antibody levels were also entered as potential confounding factors into the model. The relative risks, estimated as odds ratios with 95\% confidence intervals, were computed for tertiles of serum anti-CCP2s levels $(<15.0 ; 15.0$ to $16.2 ; \geqslant 16.3$ units $), \mathrm{C} / \mathrm{A}$ (I) ratios $(<0.86 ; 0.86$ to $0.94 ; \geqslant 0.95)$ and C/A (II) ratios $(<0.85 ; 0.86$ to $0.94 ; \geqslant 0.95)$. The tertile divisions were based on the antibody distributions among controls. The effect modification of each antibody was tested by entering interaction terms "tertile A * tertile $\mathrm{B}^{\text {" in }}$ addition to tertiles $\mathrm{A}$ and $\mathrm{B}$ into the model. The statistical significance of interaction was tested with the likelihood ratio test based on the model and expressed as an exact $\mathrm{p}$ value. 
Table 1 Average levels of antibodies to arginine (A)- and citrulline (C)-containing telopeptides of type I and II collagens, the corresponding C/A ratios and anti-CCP antibodies in future patients with rheumatoid arthritis (RA) and their controls

\begin{tabular}{|c|c|c|c|c|c|c|c|c|c|}
\hline \multirow[b]{2}{*}{ Baseline variable } & \multicolumn{3}{|l|}{ RF-positive RA } & \multicolumn{3}{|c|}{ RF-negative RA } & \multicolumn{3}{|l|}{ RA in total } \\
\hline & $\begin{array}{l}\text { Case mean } \\
\text { (SD) }\end{array}$ & $\begin{array}{l}\text { Control mean } \\
\text { (SD) }\end{array}$ & $\mathbf{p}$ & $\begin{array}{l}\text { Case mean } \\
\text { (SD) }\end{array}$ & $\begin{array}{l}\text { Control mean } \\
\text { (SD) }\end{array}$ & $\mathbf{p}$ & $\begin{array}{l}\text { Case mean } \\
\text { (SD) }\end{array}$ & $\begin{array}{l}\text { Control mean } \\
\text { (SD) }\end{array}$ & $p$ \\
\hline No. of females (\%) & $58(65.2)$ & & & $27(77.1)$ & & & 85 (68.5) & $253(68.8)$ & \\
\hline Age (years) & $45.6(13.1)$ & $45.6(13.0)$ & 0.41 & $45.6(10.2)$ & $45.6(10.2)$ & 0.52 & $45.6(12.3)$ & $45.6(12.3)$ & 0.55 \\
\hline A (I) (unit) & $10.4(6.6)$ & $9.8(3.4)$ & 0.43 & $11.3(5.7)$ & $12.1(1.0)$ & 0.68 & 10.7 (6.3) & $10.4(6.0)$ & 0.77 \\
\hline C (I) (unit) & $19.3(42.1)$ & $8.8(2.8)$ & 0.03 & $9.7(4.2)$ & $9.4(7.8)$ & 0.87 & $16.6(36.0)$ & $8.9(4.7)$ & 0.03 \\
\hline C/A (I) (ratio) & $1.9(4.4)$ & $0.9(0.1)$ & 0.04 & $0.9(0.3)$ & $0.9(0.1)$ & 0.42 & $1.7(3.8)$ & $0.9(0.1)$ & 0.04 \\
\hline A (II) (unit) & $10.4(5.3)$ & $10.0(2.9)$ & 0.47 & $10.1(3.4)$ & $10.5(6.9)$ & 0.77 & $10.3(4.9)$ & $10.1(4.4)$ & 0.71 \\
\hline C (II) (unit) & $15.2(28.0)$ & $9.0(2.5)$ & 0.04 & $9.3(2.9)$ & $9.5(6.9)$ & 0.89 & $13.6(23.9)$ & $9.1(4.2)$ & 0.04 \\
\hline C/A (II) (ratio) & $1.6(3.3)$ & $0.9(0.1)$ & 0.06 & $0.9(0.1)$ & $0.9(0.1)$ & 0.45 & $1.4(2.8)$ & $0.9(0.1)$ & 0.06 \\
\hline Anti-CCP (unit) & 219.1 (489.1) & $16.0(1.5)$ & 0.0002 & $54.7(141.7)$ & $16.5(3.5)$ & 0.12 & $172.7(426.8)$ & $16.1(2.3)$ & 0.00008 \\
\hline
\end{tabular}

Subgroup analyses were carried out among those whose time span from the baseline examination to the onset of RA was $>5$ years, and whose baseline anti-CCPs was within normal range $(<25 \mathrm{U} / \mathrm{ml})$, to control possible effects of early but still undiagnosable RA on the results.

\section{RESULTS}

Baseline levels of different autoantibodies and antibody ratios in future cases with RA and their matched controls are presented in table 1 . The mean levels of antibodies to C (I), C (II) and CCPs, and C/A (I) and C/A (II) ratios were higher in cases than controls for RF-positive RA and RA in total, whereas antibodies to A (I) or A (II) showed no case-control difference in any comparison. No antibody level or C/A ratio differed between cases with RF-negative RA and their matched controls.

Among the future cases of any RA, men had significantly higher levels of anti-CCPs and a higher C/A (I) ratio than had women, and individuals with high C/A (I) ratios had a significantly higher level of anti-CCPs and an almost significantly higher C/A (II) ratio (table 2). Among the control subjects, the correlations between sex, age and the antibodies were much weaker (table 2).

In the highest tertiles of C/A (I) and C/A (II) ratios and, in particular, in the highest tertile of serum anti-CCPs, the relative risk of RF-positive RA was significantly increased (table 3). The three antibody predictors, however, tended to confound the effects of each other, and after entering of all three into the multifactorial model, only anti-CCPs retained its statistical significance.

An examination of possible effect-modification by sex and age on the association between each antibody level and the risk of RF-positive RA revealed no significant interaction (data not shown). However, the interaction term between the C/A (II) ratio and anti-CCPs levels proved statistically significant $(p=0.02)$. The subjects ranked into the highest tertiles of both the C/A (II) ratio and anti-CCPs had a relative risk of 20.06 (95\% confidence interval, 4.37 to 92.06 ) for developing RFpositive RA compared with those in the lowest tertiles of those antibodies. A synergistic effect modification also seemed to exist for the C/A (I) ratio and anti-CCPs, but their interaction term was not statistically significant (tables 4 and 5). No effect modification was suggested between the C/A (I) and (II) ratios (data not shown).

Data analysis was also restricted to time span of $\geqslant 5$ years from baseline examination until the diagnosis of RA. The relative risks for follow-up times over 5 years did not differ notably from those for the entire follow-up (data not shown). The analysis was also carried out among those whose anti-CCPs levels were within normal limits $(<25 \mathrm{U} / \mathrm{ml})$. Again, no substantial alteration in the main results was observed. Odds

Table 2 Age- and sex-adjusted mean values $(\bar{x})$ of anti-CCP antibodies and of antibody ratios to citrulline-/arginine-containing (C/A) (I) and (II) C-telopeptides by sex and tertiles of age and each antibody among future cases of rheumatoid arthritis and their controls

\begin{tabular}{|c|c|c|c|c|c|c|c|c|c|c|c|c|c|c|c|c|c|c|c|}
\hline \multirow[b]{3}{*}{ Variable } & \multirow{3}{*}{$\begin{array}{l}\text { Category } \\
\text { tertile** }\end{array}$} & \multicolumn{6}{|c|}{ Cases of RA } & \multirow{2}{*}{\multicolumn{3}{|c|}{$\begin{array}{l}\text { Controls } \\
\text { C/A (III) ratio }\end{array}$}} & \multicolumn{9}{|c|}{ Controls } \\
\hline & & \multicolumn{3}{|c|}{ Anti-CCP (unit) } & \multicolumn{3}{|c|}{ C/A (I) ratio } & & & & \multicolumn{3}{|c|}{ Anti-CCP (unit) } & \multicolumn{3}{|c|}{ C/A (I) ratio } & \multicolumn{3}{|c|}{ C/A (II) ratio } \\
\hline & & $\overline{\mathbf{x}}$ & $r$ & p & $\overline{\mathbf{x}}$ & $r$ & p & $\overline{\mathbf{x}}$ & $r$ & $p$ & $\overline{\mathbf{x}}$ & $r$ & $p$ & $\overline{\mathbf{x}}$ & $\mathbf{r}$ & p & $\overline{\mathbf{x}}$ & $r$ & $p$ \\
\hline \multirow[t]{2}{*}{ Sext } & Men & 311.7 & & & 2.8 & & & 1.3 & & & 16.2 & & & 0.91 & & & 0.93 & & \\
\hline & Women & 108.9 & 0.23 & 0.01 & 1.2 & 0.19 & 0.04 & 1.4 & 0.01 & 0.88 & 16.1 & 0.02 & 0.66 & 0.90 & 0.02 & 0.66 & 0.90 & 0.10 & 0.05 \\
\hline Age $\neq$ & $<41$ & 139.8 & & & 1.0 & & & 1.0 & & & 16.3 & & & 0.91 & & & 0.89 & & \\
\hline \multirow[t]{2}{*}{ (years) } & 41 to 50 & 183.3 & 0.06 & 0.83 & 2.6 & 0.20 & 0.11 & 2.2 & 0.20 & 0.008 & 16.0 & & 0.82 & 0.91 & 0.06 & 0.53 & 0.91 & 0.14 & 0.03 \\
\hline & $\begin{array}{l}\geqslant 51 \\
\text { Lower }\end{array}$ & 195.0 & & & 1.3 & & & 1.0 & & & 16.1 & & & 0.89 & & & 0.93 & & \\
\hline \multirow{3}{*}{$\begin{array}{l}\text { Anti-CCP } \\
\text { (unit) }\end{array}$} & Lower & & & & 1.3 & & & 1.1 & & & & & & 0.88 & & & 0.92 & & \\
\hline & Medium & & & & 1.1 & 0.11 & 0.49 & 0.9 & 0.12 & 0.40 & & & & 0.92 & 0.14 & 0.04 & 0.93 & 0.13 & 0.04 \\
\hline & Higher & & & & 2.0 & & & 1.7 & & & & & & 0.90 & & & 0.89 & & \\
\hline$C / A(I)$ & Lower & 99.4 & & & & & & 1.0 & & & 16.0 & & & & & & 0.92 & & \\
\hline ratio & $\begin{array}{l}\text { Medium } \\
\text { Higher }\end{array}$ & $\begin{array}{r}39.5 \\
312.6\end{array}$ & 0.29 & 0.01 & & & & $\begin{array}{l}0.8 \\
2.2\end{array}$ & 0.23 & 0.06 & $\begin{array}{l}16.7 \\
16.0\end{array}$ & 0.08 & 0.32 & & & & $\begin{array}{l}0.90 \\
0.91\end{array}$ & 0.07 & 0.47 \\
\hline C/A (II) & Lower & 82.4 & & & 1.1 & & & & & & 16.7 & & & 0.91 & & & & & \\
\hline ratio & $\begin{array}{l}\text { Medium } \\
\text { Higher }\end{array}$ & $\begin{array}{l}164.7 \\
236.8\end{array}$ & 0.15 & 0.25 & $\begin{array}{l}0.8 \\
2.5\end{array}$ & 0.22 & 0.07 & & & & $\begin{array}{l}16.1 \\
15.6\end{array}$ & 0.12 & 0.09 & $\begin{array}{l}0.89 \\
0.90\end{array}$ & 0.06 & 0.52 & & & \\
\hline
\end{tabular}

*The tertiles are based on the distributions among controls; tadjusted for age only; fadjusted for sex only.

$r=$ partial correlation coefficient based on continuous variables and $p=$ statistical significance for its difference from zero. 
Table 3 Relative odds (ORs), with 95\% confidence intervals (Cls), of rheumatoid factor positive rheumatoid arthritis between tertiles* of anti-CCP antibodies and of ratios of antibodies to citrulline/arginine-containing (C/A) (I) and (II) C-telopeptides

\begin{tabular}{llllll}
\hline Antibody & Tertile* & No. of cases & No. of controls & Univariate odds OR (95\% Cl) & Multifactorial modelt OR (95\% CI) \\
\hline Anti-CCP (unit) & Lower & 15 & 83 & 1.00 & 1.00 \\
& Medium & 18 & 88 & $1.84(0.78$ to 4.34$)$ & 1.91 (0.76 to 4.80$)$ \\
& Higher & 56 & 90 & $7.25(3.06$ to 17.20$)$ & $6.12(2.44$ to 15.35$)$ \\
C/A (I) (ratio) & Lower & 15 & 71 & 1.00 & 1.00 \\
& Medium & 26 & 80 & $2.41(0.95$ to 6.10$)$ & $2.03(0.79$ to 5.23$)$ \\
C/A (II) (ratio) & Higher & 41 & 88 & $3.78(1.47$ to 9.68$)$ & 1.54 (0.98 to 6.60$)$ \\
& Lower & 25 & 86 & 1.00 & $1.13(0.49$ to 2.60$)$ \\
& Medium & 22 & 88 & $0.98(0.48$ to 2.00$)$ & 2.31 (0.93 to 5.75$)$ \\
\hline
\end{tabular}

*The tertiles are based on the distributions among controls; fadjusted for two other antibodies.

Table 4 Relative odds* (ORs), with 95\% confidence intervals (Cls), of rheumatoid factor positive rheumatoid arthritis between tertiles ratios of citrulline/arginine containing C/A (I) C-telopeptide antibody ratios in tertiles* of anti-CCP antibodies

\begin{tabular}{|c|c|c|c|c|c|c|}
\hline \multirow[b]{3}{*}{ Anti-CCP } & \multicolumn{6}{|c|}{ C/A (I) ratio } \\
\hline & \multicolumn{2}{|l|}{ Lower } & \multicolumn{2}{|c|}{ Medium } & \multicolumn{2}{|l|}{ Higher } \\
\hline & nt & OR $(95 \% \mathrm{Cl})$ & n† & OR $(95 \% \mathrm{Cl})$ & nt & OR $(95 \% \mathrm{Cl})$ \\
\hline Lower & $4 / 25$ & 1.00 & $3 / 25$ & 1.05 (0.18 to 6.01$)$ & $8 / 21$ & $4.26(0.92$ to 19.69$)$ \\
\hline Medium & $3 / 26$ & $0.79(0.12$ to 5.25$)$ & $8 / 17$ & 5.58 (1.09 to 28.62$)$ & $15 / 37$ & $7.69(1.61$ to 36.87$)$ \\
\hline Higher & $8 / 27$ & 2.26 (0.41 to 12.59$)$ & $6 / 33$ & $2.58(0.47$ to 14.10$)$ & $27 / 28$ & $13.71(2.98$ to 63.16$)$ \\
\hline
\end{tabular}

*The tertiles are based on the distributions among controls; $\dagger \mathrm{n}=$ number of cases/controls.

$p$ value for interaction $=0.28$.

Table 5 Relative odds ratios (ORs), with 95\% confidence intervals (Cls), of rheumatoid factor positive rheumatoid arthritis between tertiles* of citrulline/arginine containing C/A (II) C-telopeptide antibody ratios in tertiles* of anti-CCP antibodies

\begin{tabular}{|c|c|c|c|c|c|c|}
\hline \multirow[b]{3}{*}{ Anti-CCP } & \multicolumn{6}{|c|}{ C/A (II) ratio } \\
\hline & \multicolumn{2}{|l|}{ Lower } & \multicolumn{2}{|c|}{ Medium } & \multicolumn{2}{|l|}{ Higher } \\
\hline & $\overline{n \dagger}$ & OR $(95 \% \mathrm{Cl})$ & $\overline{n \dagger}$ & OR $(95 \% \mathrm{Cl})$ & $\overline{n \dagger}$ & OR $(95 \% \mathrm{Cl})$ \\
\hline Lower & $5 / 27$ & 1.00 & $8 / 25$ & $2.93(0.68$ to 12.67$)$ & $12 / 34$ & 3.87 (0.95 to 15.73$)$ \\
\hline Medium & $1 / 22$ & $0.31(0.03$ to 3.26$)$ & $6 / 31$ & $1.99(0.39$ to 10.08$)$ & $15 / 35$ & 6.70 (1.49 to 30.01$)$ \\
\hline Higher & $9 / 34$ & 1.76 (0.36 to 8.69$)$ & $4 / 31$ & $1.10(0.18$ to 6.69$)$ & $29 / 21$ & 20.06 (4.37 to 92.06 ) \\
\hline
\end{tabular}

*The tertiles are based on the distributions among controls; $\dagger n=$ number of cases/controls.

$p$ value for interaction $=0.02$.

ratios (95\% confidence intervals) of seropositive RA for antiCCP concentrations of $<15.0,15.0-16.2$ and $16.3-24.9 \mathrm{U} / \mathrm{ml}$ were 1.00 (reference category), $1.71(0.67-4.36)$ and 3.08 (1.11$8.47)$, respectively.

Smoking neither showed any association with the levels of anti-CCP, C/A (I) or C/A (II), nor showed any confounding effect on the results. The interaction term between the C/A (II) ratio and anti-CCP levels remained statistically significant $(\mathrm{p}=0.02)$, when smoking history (never smoked; quit; $<20$ cigarettes/day; $\geqslant 20$ cigarettes/day) was entered into the model as a potential confounding factor.

\section{DISCUSSION}

In the present study, anti-CCP levels already within the reference range $(<25 \mathrm{U} / \mathrm{ml})$ predicted the development of RFpositive RA, and the simultaneous occurrence of autoantibodies to citrullinated telopeptide of type II collagen showed a synergistic effect. Citrulline to arginine telopeptide ratios and even the single assays for antibodies to citrulline containing telopeptides also predicted RF-positive RA significantly, but anti-CCPs confounded their effects. The study material consisted of preillness serum samples from subjects who were free from RA at the baseline examination.
The significant synergism we found between anti-CCPs and type II citrullinated telopeptide was unexpected. The previous anti-CCPl was based on filaggrin-derived peptide, but the second-generation anti-CCP2s is a totally new set of several antigens, although both have surprisingly a similar brand name. The sequences of anti-CCP2 peptides have not yet been published. ${ }^{32}$ Also, the number of different peptides in the CCP2 assay is secret, but they are certainly not present in human bodies. $^{33}$ However, we have previously demonstrated that antibodies binding telopeptides are not recognising the antiCCP2s antigens. ${ }^{15}$ Although there was no linear correlation between anti-CCPs results and type I and II telopeptide antibodies, both are increased in RA. Indeed, this synergism is a new finding that we could not predict beforehand. The difference between antibodies against citrullinated type I and II collagens might then be due to a smaller number of samples of the former peptide which decreases the statistical power.

In our previous work, we wanted to characterise sequential determinants in citrullinated fibrillar collagens and selected two pairs (arginine/citrulline) of linear synthetic peptides related to the triple-helical region and another two related to the carboxyterminal telopeptide of human type II collagen. ${ }^{15}$ About half of the RA sera tested bound some of the peptides, 
usually showing more binding to the arginine- than the citrulline-containing variant. For a peptide corresponding to the most terminal part of the telopeptide, however, significant binding to the citrullinated form was seen. Similar findings were made with peptides related to the telopeptides domains of the two different $\alpha$-chains of type I collagen. ${ }^{15}$ Based on these results, we did not test any other peptides than those located at the non-helical end of type I and II collagen molecules. One of the reasons was that there was not enough serum to test several collagenous peptides.

The process of the induction of autoantibodies against citrullinated proteins is not known. Synovial tissues contain several proteins that can be citrullinated. ${ }^{4}$ Possible candidates to provoke immune responses include citrullinated $\alpha$ and $\beta$ chains of fibrin in synovial tissue ${ }^{34}$ and the Sa antigen, identified as citrullinated vimentin. ${ }^{35}$ The presence of autoantibodies to citrullinated proteins has recently been reported to predict the development of RA in of apparently healthy people $^{2021}$ and as recently reviewed ${ }^{23}$ several studies have shown that anti-CCPs antibodies predict the progression of undifferentiated arthritis to RA. The results of the current study are concordant with our previous observation that also antifilaggrin antibodies within the normal range predict the development of RF-positive RA in a linear fashion. ${ }^{16}$ It may be noted that the RF and anti-citrullinated protein/peptide antibodies both have different associations with certain features of RA like extra-articular manifestations and that anti-TNF therapy appears to affect differently RF and anti-CCPs antibody levels. ${ }^{36}$

Autoantibody positivity prior to the beginning of the clinical disease is a common finding in other autoimmune diseases, as systemic lupus erythematosus ${ }^{37}$ and insulin-dependent diabetes mellitus. ${ }^{38}$ Thus, at least in theory, it is today already possible to identify subjects at risk and even consider immunological interventions to prevent the onset of diabetes, for example, although considerable difficulties are to be expected in such approaches. ${ }^{39}$ It is likely that there are in RA several antibodies against citrullinated proteins found either in intracellular or extracellular space, many of which could be innocent in nature. On the other hand, autoantibodies against citrullinated collagens could be harmful. ${ }^{40}$ They might participate in the destruction of both cartilage and periarticular bone. It is interesting that both type I and type II collagens have a similar sequence at the carboxy telopeptides, and in RA both cartilage and periarticular bones are affected. Citrullination processes in joint collagens in RA is a demanding task to study, since the amount of citrulline could be very small and possibly subject to attack of autoantibodies against citrullinated collagens. In this respect, new methods to analyse protein citrullination ${ }^{41}$ might be helpful. At this time, however, it has been convincingly shown that both type I and type II collagen can be citrullinated in vitro ${ }^{13-15}$ and that autoantibodies to these citrullinated antigens frequently occur in the sera of RA patients. Importantly, the binding of the autoantibodies to collagens could be specifically inhibited by citrulline-containing soluble peptides. ${ }^{42}$

In conclusion, the present study shows that even low levels of anti-CCPs 2 antibodies (within the reference range, ie, below $25 \mathrm{U} / \mathrm{ml}$ ) predict in a dose-dependent manner the development of seropositive RA. Men had significantly higher levels of antiCCPs and a higher C/A (I) ratio than had women. Simultaneous occurrence of antibodies to citrullinated telopeptide of type II collagen, expressed as C/A (II) ratio, exerts a synergistic effect.

\section{ACKNOWLEDGEMENTS}

The authors gratefully acknowledge the expert technical assistance of Ms Katja Koukkula and Ms Pirjo Mäki. This study was supported in part by the Medical Research Council of the Academy of Finland and the Graduate School of In Vitro Diagnostics (M-K.K).

\section{Authors' affiliations \\ Marja-Kaisa Koivula, Departments of Clinical Chemistry, University of Oulu and University of Turku, Oulu and Turku, Finland \\ Jarmo Ramberg, Juha Risteli, Department of Clinical Chemistry, University of Oulu, Oulu, Finland}

Markku Heliövaara, Paul Knekt, Harri Rissanen, Timo Palosuo, National

Public Health Institute, Helsinki, Finland

Competing interests: None declared.

\section{REFERENCES}

1 Aho K, Heliövaara M. Risk factors for rheumatoid arthritis. Ann Med 2004;36:242-51.

2 Manfredsdottir VF, Vikingsdottir T, Jonsson T, Geirsson AJ, Kjartansson O, Heimisdottir $M$, et al. The effects of tobacco smoking and rheumatoid factor seropositivity on disease activity and joint damage in early rheumatoid arthritis. Rheumatology (Oxford) 2006;45:734-40.

3 Klareskog L, Stolt P, Lundberg K, Kallberg H, Bengtsson C, Grunewald J, et al. A new model for an etiology of rheumatoid arthritis: smoking may trigger HLA-DR (shared epitope)-restricted immune reactions to autoantigens modified by citrullination. Arthritis Rheum 2006;54:38-46.

4 Nijenhuis S, Zendman AJW, Vossenaar ER, Pruijn GJM, van Venrooij WJ. Autoantibodies to citrullinated proteins in rheumatoid arthritis: clinical performance and biochemical aspects of an RA-specific marker. Clin Chem Acta 2004;350:17-34

5 Yamada R, Suzuki A, Chang X, Yamamoto K. Citrullinated proteins in rheumatoid arthritis. Front Biosci 2005; 10:54-64.

6 Worthington J, John S. Association of PADI4 and rheumatoid arthritis: a successful multidisciplinary approach. Trends Mol Med 2003;9:405-7.

7 Yamada R, Suzuki A, Chang X, Yamamoto K. Peptidylarginine deiminase type 4: identification of a rheumatoid arthritis-susceptible gene. Trends Mol Med 2003;9:503-8.

8 Vossenaar ER, Radstake TR, van der Heijden A, van Mansum MA, Dieteren C, de Rooij DJ, et al. Expression and activity of citrullinating peptidylarginine deiminase enzymes in monocytes and macrophages. Ann Rheum Dis 2004;63:373-81.

9 Chang X, Yamada R, Suzuki A, Kochi Y, Sawada T, Yamamoto K. Citrullination of fibronectin in rheumatoid arthritis synovial tissue. Rheumatology (Oxford) 2005;44:1374-82.

10 Kinloch A, Tatzer V, Wait R, Peston D, Lundberg K, Donatien P, et al. Identification of citrullinated alpha-enolase as a candidate autoantigen in rheumatoid arthritis. Arthritis Res Ther 2005;7:R1421-9.

11 Rogers GE, Taylor LD. The enzymic derivation of citrulline residues from arginine residues in situ during the biosynthesis of hair proteins that are cross-linked by isopeptide bonds. Adv Exp Med Biol 1977;86A:283-94.

12 Okazaki Y, Suzuki A, Sawada T, Ohtake-Yamanaka M, Inoue T, Hasebe T, et al. Identification of citrullinated eukaryotic translation initiation factor 4 GI as novel autoantigen in rheumatoid arthritis. Biochem Biophys Res Commun 2006;341:94-100.

13 Burkhardt H, Sehnert B, Bockermann R, Engström A, Kalden JR, Holmdahl R. Humoral immune response to citrullinated collagen type II determinants in early rheumatoid arthritis. Eur J Immunol 2005;35:1643-52.

14 Suzuki A, Yamada R, Ohtake-Yamanaka M, Okazaki Y, Sawada T, Yamamoto K. Anti-citrullinated collagen type I antibody is a target of autoimmunity in rheumatoid arthritis. Biochem Biophys Res Commun 2005;333:418-26.

15 Koivula MK, Åman S, Karjalainen A, Hakala M, Risteli J. Are there autoantibodies reacting against citrullinated peptides derived from type I and type II collagens in patients with rheumatoid arthritis? Ann Rheum Dis 2005;64: 1443-50.

16 Aho K, Palosuo T, Heliövaara M, Knekt P, Alha P, von Essen R. Antifilaggrin antibodies within "normal" range predict rheumatoid arthritis in a linear fashion. J Rheumatol 2000;27:2743-6.

17 Aho K, Palosuo T, Raunio V, Puska P, Aromaa A, Salonen JT. When does rheumatoid disease start? Arthritis Rheum 1985;28:485-9.

18 Kurki P, Aho K, Palosuo T, Heliövaara M. Immunopathology of rheumatoid arthritis: antikeratin antibodies precede the clinical disease. Arthritis Rheum 1992;35:914-7.

19 Aho K, von Essen R, Kurki P, Palosuo T, Heliövaara M. Antikeratin antibody and antiperinuclear factor as underlying markers for rheumatoid disease process. $J$ Rheumatol 1993;20:1278-81.

20 Rantapää-Dahlqvist S, de Jong BAW, Berglin E, Hallmans G, Wadell G, Stenlund $\mathrm{H}$, et al. Antibodies against cyclic citrullinated peptide and $\lg A$ rheumatoid factor predict the development of rheumatoid arthritis. Arthritis Rheum 2003;48:2741-9.

21 Nielen MMJ, van Schaardenburg D, Reesink HW, van de Stadt RJ, van der Horst-Bruinsma IE, de Koning MHMT, et al. Specific autoantibodies precede the symptoms of rheumatoid arthritis: a study of serial measurements in blood donors. Arthritis Rheum 2004;50:380-6.

22 Schellekens GA, Visser H, de Jong BAW, van den Hoogen FHJ, Hazes JMW, Breedveld FC, et al. The diagnostic properties of rheumatoid arthritis antibodies recognizing a cyclic citrullinated peptide. Arthritis Rheum 2000;43:155-63. 
23 Avouac J, Gossec L, Dougados M. Diagnostic and predictive values of anti-CCP (cyclic citrullinated protein) antibodies in rheumatoid arthritis: a systematic literature review. Ann Rheum Dis 2006;85:845-51

24 Koivula MK, Ramberg J, Åman S, Karjalainen A, Hakala M, Risteli J. Sensitive immunoassays for the autoantibodies reacting against citrullinated carboxyterminal telopeptides of type I and type II collagens in patients with rheumatoid arthritis. Clin Chem Lab Med 2005;43:1400-5.

25 Reunanen A, Aromaa A, Pyörälä K, Punsar S, Maatela J, Knekt P. The Social Insurance Institution's coronary heart disease study. Baseline data and 5-years mortality experience. Acta Med Scand 1983;214(suppl 673):1-120.

26 Aho K, Heliövaara M, Knekt P, Reunanen A, Aromaa A, Leino A, et al. Serum immunoglobulins and the risk of rheumatoid arthritis. Ann Rheum Dis 1997:56:351-6.

27 Heikkilä R, Aho K, Heliövaara M, Knekt P, Reunanen A, Aromaa A, et al. Serum androgen-anabolic hormones and the risk of rheumatoid arthritis. Ann Rheum Dis 1998;57:281-5.

28 Myllykangas-Luosujärvi R, Aho K, Kautiainen H, Isomäki H. Shortening of life span and causes of excess mortality in a population-based series of subjects with rheumatoid arthritis. Clin Exp Rheumatol 1995;13:149-53.

29 Hakala M, Pöllänen R, Nieminen P. The ARA 1987 revised criteria select patients with clinical rheumatoid arthritis from a population based cohort of subjects with chronic rheumatic diseases registered for drug reimbursement. J Rheumatol 1993;20:1674-8

30 Kaipiainen-Seppänen O, Aho K, Isomäki H, Laakso M. Incidence of rheumatoid arthritis in Finland during 1980-1990. Ann Rheum Dis 1996;55:608-11.

31 Breslow NE, Day NE. Statistical methods in cancer research. Vol. 1. The analysis of case-control studies. Lyon: JACR Scientific Publications 1980;32:248-79.

32 Zendman A, van Venrooij W, Prujin G. Use and significance of anti-CCP autoantibodies in rheumatoid arthritis. Rheumatology (Oxford) 2006;45:20-5.
33 Kinloch AJ, Lundberg KE, Moyes D, Venables PJ. Pathogenic role of antibodies to citrullinated proteins in rheumatoid arthritis. Expert Rev Clin Immunol 2006;2:365-75.

34 Masson-Bessiere C, Sebbag M, Girbal-Neuhauser E, Nogueira L, Vincent C, Senshu $T$, et al. The major synovial targets of the rheumatoid arthritis-specific antifilaggrin autoantibodies are deiminated forms of the $\alpha$ - and $\beta$-chains of fibrin. J Immunol 2001;166:4177-84.

35 Vossenaar ER, Despres N, Lapointe E, van der Heijden A, Lora M, Senshu T, et al. Rheumatoid arthritis specific anti-SA antibodies target citrullinated vimentin. Arthritis Res Ther 2004;6:R142-50.

36 Van der Cruyssen B, Peene I, Cantaert T, Hoffman IE, De Rycke L, Veys EM, et al Anti-citrullinated protein/peptide antibodies (ACPA) in rheumatoid arthritis: specificity and relation with rheumatoid factor. Autoimmun Rev 2005;4:468-74

37 Aho K, Koskela P, Mäkitalo R, Heliövaara M, Palosuo T. Antinuclear antibodies heralding the onset of systemic lupus erythematosus. J Rheumatol 1992;19:1377-9.

38 Tuomilehto J, Zimmet P, Machay IR, Koskela P, Vidgren G, Toivanen L, et al. Antibodies to glutamic acid decarboxylase as predictors of insulin-dependent diabetes mellitus before clinical onset of disease. Lancet 1994;343:1383-5.

39 Couzin J. Clinical trials. Diabetes' brave new world. Science 2003;300:1862-5

40 Risteli J, Koivula MK, Risteli J. Citrullinated collagens in the pathogenesis of rheumatoid arthritis. Expert Rev Clin Immunol 2007;3:184-94.

41 Holm A, Rise F, Sessler N, Sollid LM, Undheim K, Flechenstaein B. Specific modifications of peptide-bound citrulline residues. Anal Biochem 2006;352:68-76.

42 Koivula MK, Åman S, Alasaarela E, Karjalainen A, Hakala M, Risteli J. Inhibitory characteristics of citrullinated telopeptides of type I and II collagens for autoantibody binding in patients with rheumatoid arthritis. Rheumatology (Oxford) 2006;45:1364-9.

\section{BNF for Children 2006, second annual edition}

In a single resource:

- guidance on drug management of common childhood conditions

- hands-on information on prescribing, monitoring and administering medicines to children

- comprehensive guidance covering neonates to adolescents

For more information please go to bnfc.org 